\title{
A new genus and species of stygobitic paramelitid amphipod from the Pilbara, Western Australia
}

\author{
Terrie L. Finston, Michael S. Johnson and Brenton Knott \\ School of Animal Biology (M092), University of Western Australia, 35 Stirling Highway, \\ Crawley, Western Australia 6009, Australia
}

\begin{abstract}
The Pilbara region of Western Australia contains a diverse and endemic groundwater fauna dominated by crustaceans, with amphipods being a conspicuous component of many communities. Previous morphological and molecular research has demonstrated the need for revision of the current amphipod taxonomy. Specifically, examples of cryptic speciation and of morphological variation within single species suggest that a combined approach is needed to address the taxonomic gap. In this paper we use molecular and morphological evidence to show the distinctiveness of a new genus and species of stygobitic amphipod, Kruptus linnati, known from Spearhole Creek in the Pilbara.
\end{abstract}

Key words: allozymes, crangonyctoid, morphology, Neoniphargidae, taxonomy

\section{INTRODUCTION}

The Pilbara is a large $\left(178000 \mathrm{~km}^{2}\right)$ semiarid bio-region in the northwest of Western Australia. The region is rich in iron ore, hence it is an area of significant mining activity. Below the arid landscape, the Pilbara hosts a rich groundwater fauna (Humphreys 1999, 2001). A recent survey suggested the presence of more than 150 groundwater species, many of which are new to science, and of which nearly $60 \%$ are endemic to the area (Eberhard et al. 2005a). Amphipods are an abundant component of the groundwater fauna of the Pilbara. So far, 17 species of amphipods within the family Paramelitidae Bousfield 1977 have been described from the Pilbara (Bradbury and Williams 1997a, Bradbury 2000), and there are records of at least two additional families present. Specimens of Melitidae Bousfield 1973 and Neoniphargidae Bousfield 1977 were collected during a survey of the groundwater fauna of the Pilbara conducted by the Department of Environment and Conservation (DEC; S. Halse, pers. comm.).

The taxonomy of the amphipods of the Pilbara is poorly resolved. Allozymes suggest the presence of many undescribed species (Finston and Johnson 2004). Further, morphological interpretation rarely coincides with molecular diversity. For example, the 14 species of Chydaekata Bradbury 2000, described from Ethel Gorge in the upper Fortescue River basin northwest of Newman, W.A., suggest morphological diversity that is not matched by molecular diversity; neither allozymes nor mtDNA indicate the presence of more than one species of Chydackata in the area (Finston it al. 2004; Finston et al. 2007). In contrast, molecular diversity in Pilbarus Bradbury and Williams 1997a and Chydaekata is associated with separate tributaries, but no morphological characters have been found to differentiate the distinct mtDNA lineages (Finston et al. 2007). Lefébure et al. (2006) attribute the preponderance of cryptic species in the groundwater to constraints on form or convergence of characters in extreme environments. The potential for cryptic diversity, in combination with historical difficulties with morphological taxonomy of the amphipods of the Pilbara, indicates the need for molecular assistance to guide the placement of taxonomic boundaries. This paper utilises a combined approach towards documentation of the diversity of amphipod species in the groundwater of the Pilbara.

The Giles Mini site (231 $\left.17^{\prime} 06^{\prime \prime} \mathrm{S}, 119^{\circ} 09^{\prime} 54^{\prime \prime} \mathrm{E}\right)$ lies on Spearhole Creek, in the upper Fortescue River catchment, at the western end of the Ophthalmia Range. Uplift of shale layers and bedrock along the Ophthalmia fault has resulted in the presence of multiple, confined aquifers in the region, which are overlain with a shallow layer of calcrete (Harmsworth et al. 1990; Jason Pepper, pers. comm.). The presence of confined aquifers could provide the isolation necessary for the evolution of multiple species, each restricted to a different aquifer. Indeed, allozyme comparisons revealed the presence of four genetic groups of amphipods 
in the area, two in the shale, and two in the calcrete (Finston and Johnson 2004). According to the allozymes, all four groups were paramelitids, and one showed both morphological and molecular affinities to Chydackata, a widespread genus in the upper Fortescue River basin. The other three groups were not identified. One group, found in six bores, was relatively widespread in the shale, suggesting that movement does occur between formations; perhaps through fissures in the rock (Finston and Johnson 2004). The second group was found in a single bore, also in shale, and the third unidentified group occurred in a single bore in a calcrete aquifer. The present study utilizes morphology to assess the distinctiveness of the widespread allozyme group found in six bores. We use the combined results to describe a new genus and species of amphipod from Spearhole Creek.

\section{METHODS}

\section{Collections and allozyme analysis}

Groundwater amphipods were collected from eight bores from the Giles Mini site in 2001 and 2002, using standard methods (Eberhard et al. 2005b; see Table 1, Figure 1). The bores were sampled along a $3 \mathrm{~km}$ transect, and the samples were included in a regional study of allozyme diversity in the amphipod fauna in the Pilbara (Finston and Johnson 2004). Two shallow bores into calcretes were sampled, and the other six bores sampled aquifers in shale (Dale's Gorge, Whaleback and Joffre formations; Table 1), at depths ranging from 54 to $112 \mathrm{~m}$. Due to the difficulties involved with sampling stygofauna (limited access to the groundwater, temporal variation in recharge and spatial variation in aquifer yield; Eberhard et al. 2005a) sample sizes were small, ranging from 3 to 30 amphipods per bore. In total, 100 individuals were analysed for variation at between nine and fifteen allozyme loci, as described in Finston and Johnson (2004). For the present paper, we have re-analysed the data for the nine loci for which we have population data (due to their small size, individuals could not be analysed for all 15 loci; a smaller subset of individuals was analysed for variation at the additional six loci) from Finston and Johnson (2004) for the Spearhole Creek samples. We also included a single multilocus genotype from an individual collected at the Seven Mile Creek, which showed genetic affinities to one of the allozyme groups from Spearhole Creek. We quantified the divergence between genetically distinct groups in two ways, Nei's genetic distance (D; Nei 1972) and the proportion of loci that were diagnostic, i.e. those loci sharing no alleles between a pair of groups. We used multidimensional scaling (MDS) of the matrix of Nei's D to illustrate the genetic relationships.

\section{Morphological assessment}

A two-step approach was used to assess the taxonomic status of the widespread genetic group. First, existing keys and descriptions of the Australian amphipod fauna (Williams and Barnard 1988; Bradbury and Williams 1999; Lowry and Springthorpe 2001) were used to identify the specimens to the lowest taxonomic level possible. Second, to assess the generic and familial affinities of the specimens, we compiled 26 diagnostic characters from the generic descriptions and taxonomic keys of Australian freshwater amphipods (Williams and Barnard 1988; Bradbury and Williams 1996, 1997, 1999; Bradbury 2000) and recorded character states for representatives of each genus described from the Pilbara (Pilbarus Bradbury and Williams 1997, Chydaekata, Molina Bradbury 2000) and the specimens from Spearhole Creek. In addition to the described genera, we also included two potential sister taxa in the analysis. Specimens of Neoniphargidae from the Robe and DeGrey River

Table 1 Bores sampled for the present study, lithology (geological formation and depth targeted by the bore), allozyme group and number (n) analysed, and Western Australian Museum voucher numbers for the material used.

\begin{tabular}{lllll}
\hline Bore & Target geology & Depth $(\mathbf{m})$ & Allozyme group $^{*}(\mathbf{n})$ & Voucher number \\
\hline GM019 & Multiple Whaleback Shale & 104 & $\mathrm{H}(13)$ & WAM C40034 \\
GM027 & Joffre & 62 & $\mathrm{H}(3)$ & \\
GM039 & Multiple Whaleback Shale & 70 & $\mathrm{H}(12)$ & WAM C40035 \\
GM049 & Dale's Gorge & 84 & $\mathrm{H}(8)$ & WAM C40036 \\
GM069 & Dale's Gorge & 112 & $\mathrm{G}(5), \mathrm{H}(25)$ & WAM C40037 \\
GM118 & Multiple Whaleback Shale & 54 & $\mathrm{H} \mathrm{(4)}$ & WAM C40038, WAM C40039 \\
GMP22 & calcrete & 40 & $\mathrm{I} \mathrm{(24)}$ & WAM C40040 \\
GMP77 & calcrete & 23 & $\mathrm{~F} \mathrm{(6)}$ & \\
\hline
\end{tabular}

* groups as assigned in Finston and Johnson (2004). 


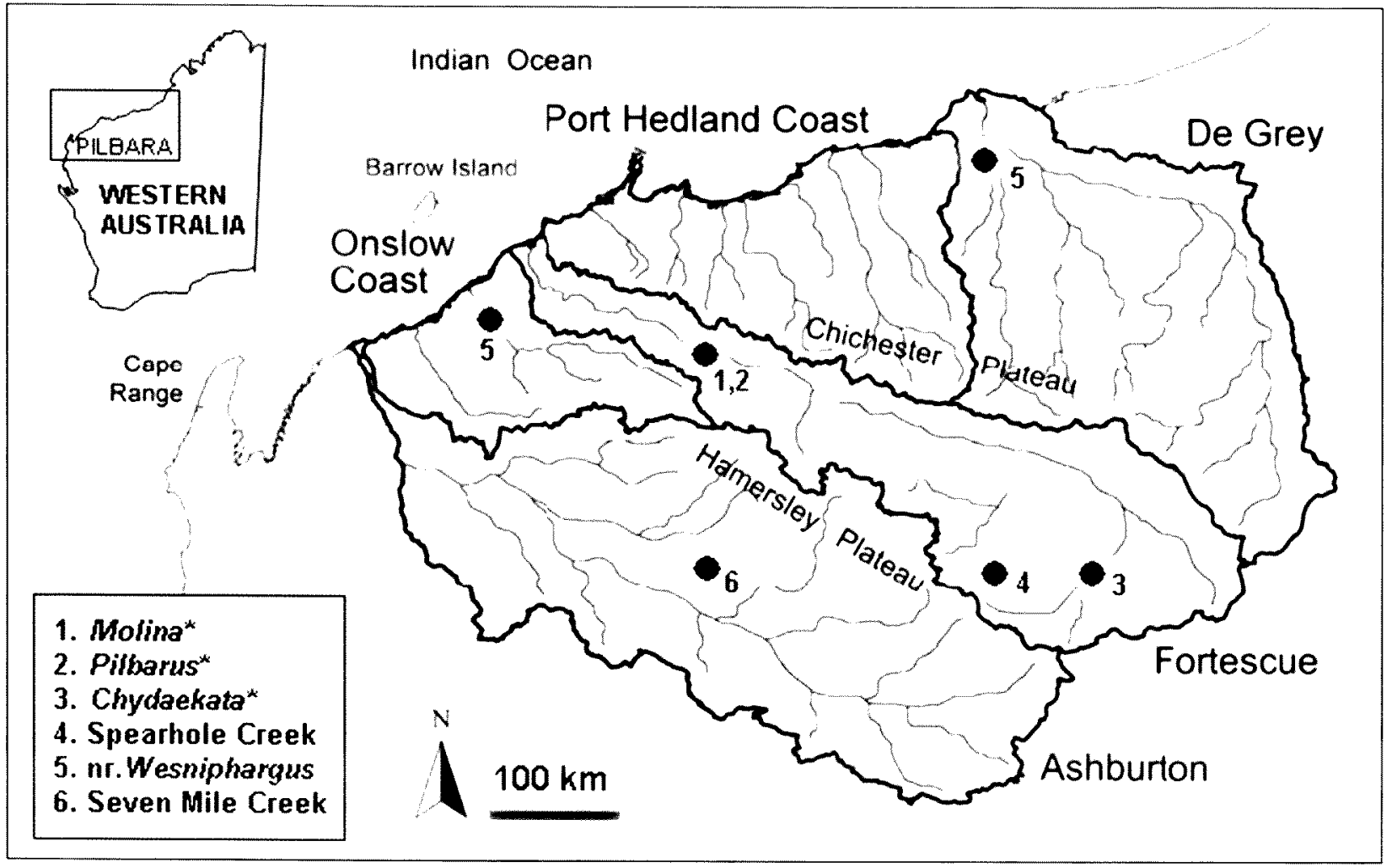

Figure 1 Map of sampling locations or type localities $\left(^{*}\right)$ for specimens used in the present study. Names and outlined areas indicate drainage basins.

basins in the Pilbara, most closely resembling Wesniphargus Williams and Barnard 1988 (herein referred to as 'nr. Wesniphargus'), were included as was Protocrangony fontinalis Nicholls 1926 from the Paramelitidae. Two species of the genus Nedsia Barnard and Williams 1995 from the family Melitidae were included as outgroups. Character states for Pilbarus millsi Bradbury and Williams 1997, Chydaekata acuminata Bradbury 2000, C. brachybasis Bradbury 2000, C. nudula Bradbury 2000, C. scopula Bradbury 2000, Molina pleobranchos Bradbury 2000, Protocrangonyx fontinalis, Nedsia douglasi Barnard and Williams 1995, and $N$. straskraba Bradbury and Williams 1996 were determined from the original descriptions. Character states for the specimens from Spearhole Creek were obtained from examination of preserved material as follows: we examined 14 specimens of the widespread genetic group from five bores (five males, five females, four juveniles). Three specimens belonging to two presumptive taxa of nr. Wesmiphargus, nr. Wesmiphargus (Robe), $\mathrm{n}=2$ and nr. Wosniphargus (DeGrey), $\mathrm{n}=1$, were loaned by the DEC and dissection was not permissible. Externally, the specimens matched the description of the genus Wesniphargus (Williams and Barnard 1988), with one major exception - our specimens lacked eyes. Of the 26 characters, most (21) were observable without dissection. As these characters matched the description of Wesniphargus, the remaining features (presence of inner lobes on the lower lip, rugosity on the maxilliped palps, and three characteristics of the mandibular palp) were assumed also to match the description of the genus and were scored as per the description. In addition, we had to make assumptions about the gender of these specimens. All three specimens had asthetascs on antenna 1 and calceoli on antenna 2 , hence we assumed that these specimens were males, as per the description. In total, 11 species from six genera and three families were included in the comparison with the specimens from Spearhole Creek. We did not include all species of Chydrakata and Netsia because the analysis was intended simply to assess morphological affinities at the generic and familial levels.

A data matrix of the scores of 12 taxa for the 26 characters was constructed using NDE 5.0 (Page 2001), and all characters were included as unordered and unweighted. Phylogenetic analysis of this matrix involved a heuristic search using parsimony and tree bisection reconnection (TBR) branch swapping, performed in PAUP (Swofford 2001), with the starting tree obtained by step-wise addition. A $50 \%$ majority rule consensus tree was obtained from 100 bootstrap replicates. The two species of Nedsin were used as the outgroup. 


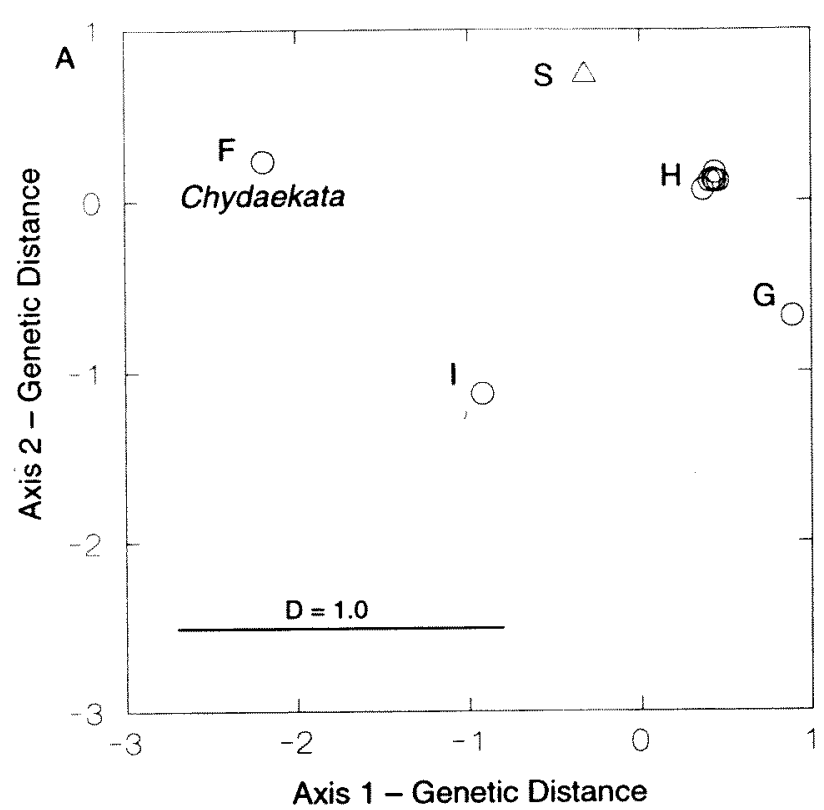

Figure 2 MDS of Nei's (1972) genetic distance D between multilocus genotypes pooled for each bore at Spearhole Creek. Circles = genotypes from Spearhole Creek, triangle = genotype from Seven Mile Creek. Genetic groups F-I as in Finston and Johnson (2004); $\mathrm{S}=$ Seven Mile Creek.

\section{RESULTS}

\section{Allozymes}

Four genetic groups were detected in the samples from Giles Mini (Table 1; group designations as in Finston and Johnson (2004); Figure 2). The most common group, $H$, was composed of 65 individuals from six bores (Table 1 ), and represents the new genus and species described in this paper. Groups F, G, and I were found in single bores (Table 1). Group F, represented by six individuals from bore GM077, showed both morphological and molecular affinities to Chydaekata (Finston and Johnson 2004). This genus differed from groups $G, H$ and I by genetic distances ranging from 1.08 to 3.53 (Table 2) and in the high proportion of diagnostic loci, which ranged from 0.44 to 0.89 (Table 2). Group $\mathrm{H}$ differed from all other groups by genetic

Table 2 Measures of genetic differentiation among allozyme groups. Above diagonal: Nei's (1972) genetic distance. Below diagonal: proportion of loci showing allelic substitutions between groups.

\begin{tabular}{lccccc}
\hline Group & F & G & H & I & S \\
\hline F & $\times$ & 3.53 & 1.98 & 1.08 & 1.49 \\
G & 0.71 & $\times$ & 0.71 & 1.04 & 1.06 \\
H & 0.33 & 0.50 & $\times$ & 1.09 & 0.78 \\
I & 0.47 & 0.79 & 0.27 & $\times$ & 1.44 \\
$\mathrm{~S}$ & 0.57 & 0.79 & 0.53 & 0.36 & $\times$
\end{tabular}

distances of 0.71 to 1.98 , and in proportions of diagnostic loci from 0.22 to 0.56 (Table 2). The smallest distance between groups occurred between groups $G$ and $H$, where $D$ was 0.71 and the proportion of diagnostic loci was 0.22 (Table 2). The genetic distance between group $H$ and the individual from Seven Mile Creek, which showed some affinities to group $\mathrm{H}$ in a previous study (Finston and Johnson 2004) was 0.78, and the proportion of diagnostic loci between the two groups was 0.56 .

\section{Morphological assessment}

The specimens from group $\mathrm{H}$ could not be identified to species using existing keys and descriptions. They fit the definition of Williams and Barnard (1988) for crangonyctoid amphipods, namely having a prominent third uropod, which is bi-ramous and with the inner ramus reduced, prominent mandibular palps, accessory flagellum present on antenna 1, and the presence of simple sternal gills. If we follow strictly the key of Bradbury and Williams (1999), we fail to differentiate our specimens as either Corophiidae or Crangonyctoidea, due to the presence of an accessory flagellum on antenna 1 (Crangoncytoid) in combination with an entire telson, lacking any notching (Corophiidae). However, if we accept that crangonyctoids may have an entire telson (e.g. Protocrangonyx Nicholls 1926), then our specimens key to the family Neoniphargidae, due to the presence of rugosities on the gnathopods. Within the Neoniphargidae, the key fails at the first couplet, because the sternal gills in our specimens are small and bud-shaped, not sausageshaped, nor dendritic. Further, all neoniphargids species so far described have rugosities on the prodopus and the maxillipedal palp, whereas

Table 3 Characteristics of specimens from Group $\mathrm{H}$ and the family to which the character belongs. $\mathrm{N}=$ Neoniphargidae, $\mathrm{P}=$ Paramelitidae.

\begin{tabular}{lc}
\hline Character & Family \\
\hline Urosomes nearly smooth & $\mathrm{N}$ \\
Coxae reduced, narrow & $\mathrm{P}$ \\
Antennal sinus shallow & $\mathrm{P}^{*}$ \\
Lower lip with weak inner lobes & $\mathrm{N}$ \\
Outer plate of maxilla 1 with $\sim 10$ apical robust setae & $\mathrm{P}$ \\
Pereopod 7 longest & $\mathrm{P}$ \\
Telson entire & $\mathrm{N}$ \\
Apices of telson with one seta & $\mathrm{P}$ \\
Uropod 3 terminal article lacking & $\mathrm{P}^{*}$ \\
Palmar setae of gnathopods simple & $\mathrm{P}^{*}$ \\
Sternal gills present on peraeon 7 & $\mathrm{P}$ \\
Distal article of uropod 3 absent & $\mathrm{P}^{*}$ \\
Rugosities present on gnathopods & $\mathrm{N}$ \\
\hline
\end{tabular}

* indicates character is within acceptable range, but is not the usual state. 
A

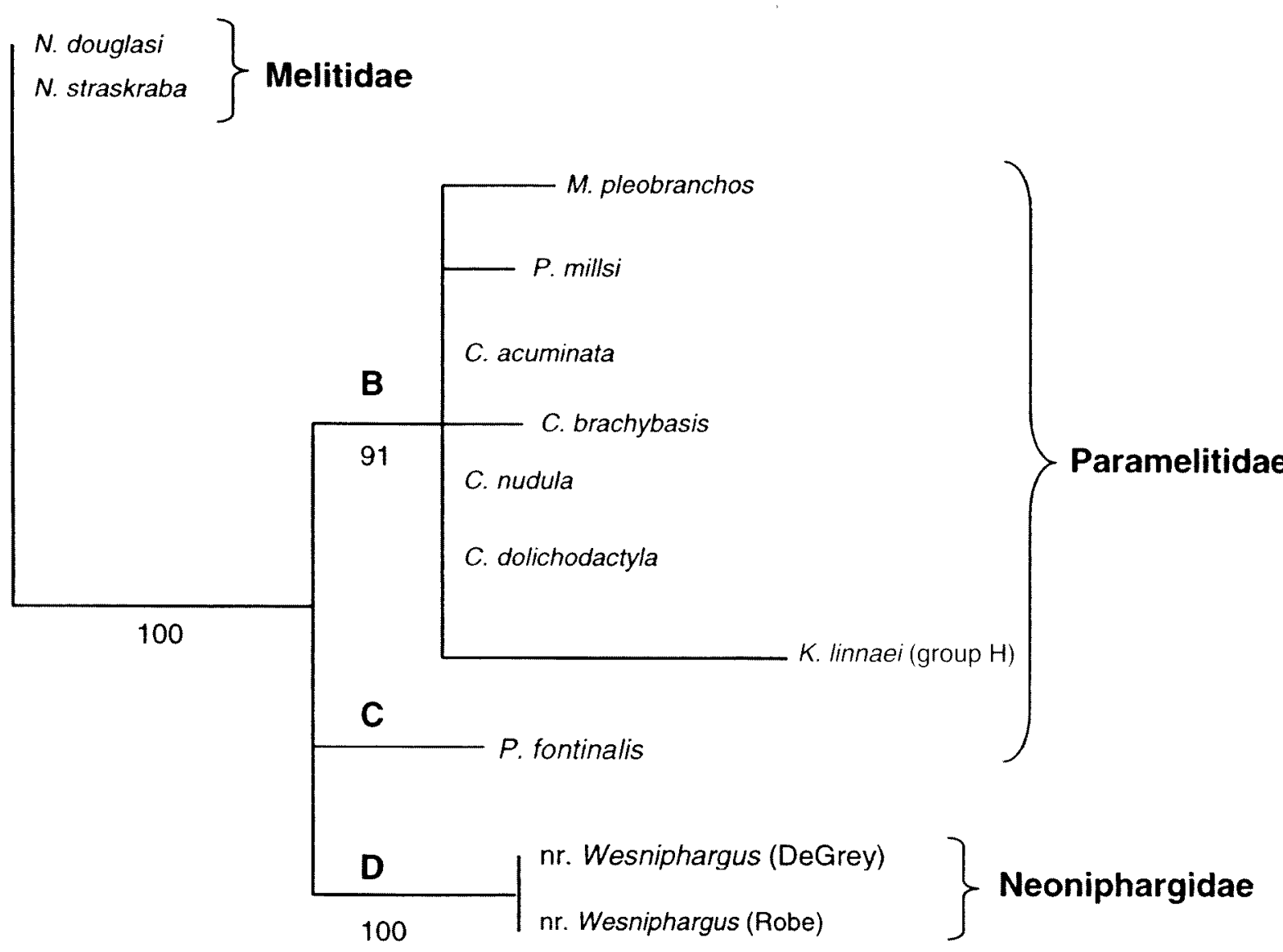

Figure $350 \%$ majority rule consensus tree for morphological character state data for known species of paramelitids from the Pilbara, and two representatives of neoniphargids from the DeGrey and Robe River basins. Two species of the melitid genus Nedsia were used as the outgroup. Clades are labelled A-D, and bootstrap values shown below branches.

rugosities are limited to the ischium and merus in the Giles group $H$ specimens. In addition, the specimens from group $\mathrm{H}$ lack the body type of the neoniphargids, such as a short and deep body, deep coxae, and lobate carpi of the gnathopods. Although keying to the neoniphargids, several characters place the Giles group H specimens with the Paramelitidae, such as reduced coxae, the presence of sternal gills on the $7^{\text {th }}$ pereopod, and the absence of well-developed inner lobes of the lower lip (Table 3). If we assume our specimens are paramelitids, despite the rugose gnathopods, then our specimens key to Protocrangonyx fontinalis, due to the presence of simple sternal gills and the telson being entire. Despite this superficial similarity, our specimens clearly are not $P$. fontinalis, which has many characteristics that differ from the group $H$ specimens, including the lack of calceoli, an accessory flagellum on antenna 1 of only two articles, the presence of a coxal gill on gnathopod 2, the lack of a coxal gill on pereopd 7 , the presence of large, strongly oblique gnathopods, and short carpi on gnathopod 2, the proportions of article 1 of the mandibular palp being approximately as long as wide, and having long posterior setae on perepods 3 and 4 .

A heuristic phylogenetic analysis of 26 diagnostic characters (Table 4) showed four clades (Figure 3). Clade A contained the melitid outgroup (Nedsia), clade B contained the paramelitids excepting Protocrangonyx, clade $C$ contained Protocrangony $x$, and clade D contained the neoniphargids (Figure 3). The specimens from group $\mathrm{H}$ occurred as a long branch in the paramelitid clade (clade B). The taxonomic position of Protocrangonyx was unresolved, falling outside of the paramelitid clade (Figure 3). Bootstrap support was high for both the paramelitid $(91 \%)$, and the neoniphargid $(100 \%)$ clades. The group $\mathrm{H}$ specimens share many characteristics with the other paramelitid genera, and in particular, with Molina. The two taxa share such traits as the coxal gills extending to segment 7 and possessing a full set of sternal gills on sternites 2-7. Nevertheless, group $\mathrm{H}$ individuals differed from Molina in eight characters (Table 5), 
Table 4 Characters and character states used for classification of known species of paramelitids and undescribed neoniphargids from the Pilbara. Two species of Nedsia (melitid) were used as outgroups.

1. Number of articles on accessory flagellum A1: 1. $<3$ (short)

2. $\geqslant 3$ (long)

2. Inner ramus U3:
0 . short or absent
1. moderately elongate; $\geqslant 1 / 3$ length outer

3. Mandibular palp:
0 . reduced (2 articles)
1. prominent ( 3 articles)

4. Calceoli on A2 (male):
0 . absent
1. present

5. A2 length of flagellum:

0 . $\leqslant$ length of peduncle

1. > length of peduncle

6. Coxae:
0 . reduced
1. intermediate
2. expanded

7. First location of coxal gills:
0.2
1. 3

8. Last location of coxal gills:
0.6
1. 7

9. Sternal gills:
0 . absent
1. partial set $(6-7)$
2. near full set $(2-6$ or $3-6)$
3. full set $(2-7)$

10. Palmar angle G1:
0 . strongly oblique
1. weakly oblique
2. transverse

11. Palmar angle G2:
0 . strongly oblique
1. weakly oblique
2. transverse

12. Carpus of G2:
0 . short; $\leqslant 50 \%$ prodopus
1. long; $\approx$ prodopus

13. Telson cleftness:
$0.0 \%$ (entire)
1. $<50 \%$
2. $\geqslant 50 \%$

\section{Basio-facial seta $\mathrm{U} 1$ :}

0 . always absent

1. sometimes or always present

15. Inner lobes lower lip:
0 . absent
1. present

16. Calceoli on peduncle:
0 . absent
1. present

17. Rugosities on gnathopods:
0 . absent
1. present

18. Rugosities on maxilliped palp:
0 . absent

1. present

19. Type of sternal gills:
0 . simple or absent
1. dendritic or lumpy

20. Number of articles in pleopod rami:
0 . short (3-7)

1. long (8-11)

21. Distal article of outer ramus of uropod 3:

0. absent
1. present

22. Article 1 of mandibular palp:

0 . length $\approx$ width

1. length noticeably longer than width

23. Article 2 of manibular palp:

0 . with few setae

1. moderately setose

24. Posterior setae on article 2 of pereopods 3 and 4:

0 . short

1. long

25. Distal margin of coxa 4 :
0. not excavate
1. excavate

26. Mandibular palp article 3:
0 . lacking $C$ setae
1. bearing $C$ setae 

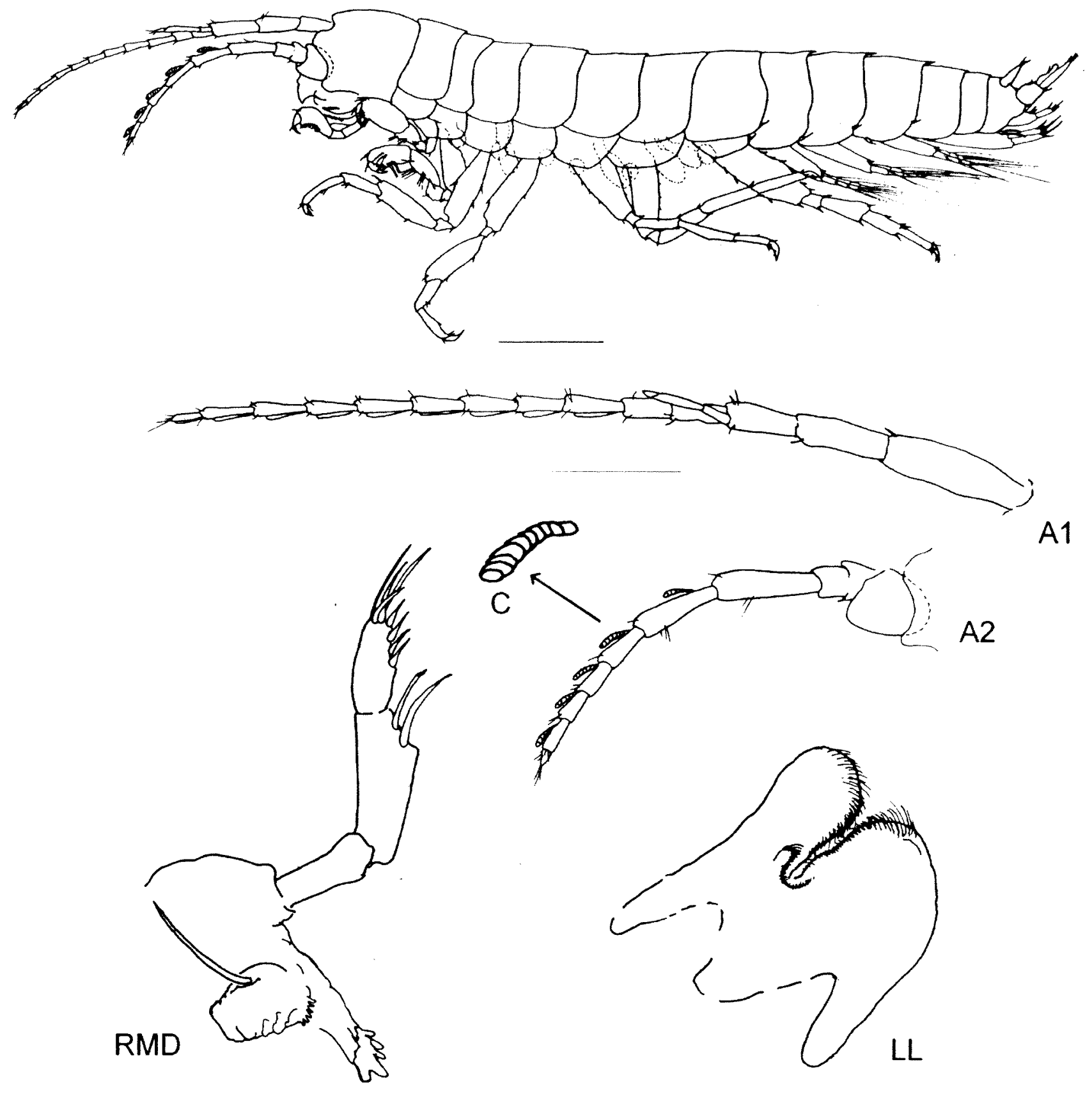

Figure 4 Kruptus limai sp. nov, holotype male $2.4 \mathrm{~mm}$, whole animal (top), antennae (A), calceolus (C), mandible (MD), lower lip (LL), $R=$ right, $L=$ left. Scale lines $=200 \mu \mathrm{m}$

including the shape of the sternal gills (Figure 4; simple buds versus sausage-shaped, respectively), the number of articles in the accessory flagellum (Figure 4; three versus six, respectively), the presence (group H) or absence (Molima) of calceoli on antenna 2 (Figure 4), cleftness of the telson (Figure $5 ; 0 \%$ and $80 \%$, respectively), and the presence (group $\mathrm{H}$ ) or absence (Molina) of rugosity on the gnathopods (Figure 5). In comparison, the number of character differences between other pairs of paramelitid genera range from two between Pilbarus and Chydackata the absence or presence of sternal gills and the shape of gnathopod 2) to four between Pilbarts and Molma. While the specimens from group $H$ share the character of rugosities on the gnathopods with the specimens of $\mathrm{nr}$. Wesmiphargus, they differ in 19 other characters, including the number of articles in the accessory flagellum of antenna 1 , the relative length of the flagellum to the peduncle of antenna 2, the location of the coxal and sternal gills, the shape of the gnathopods and relative size of the carpus, the cleftness of the telson, type of sternal gills, and size and setation of the 
Table 5 Character matrix for known species of Pilbara paramelitids and undescribed neoniphargids. Nedsia (melitid) is used as an outgroup. Character states that are inapplicable are scored as - in the matrix. nr. Wes $=$ nr. Wesniphargus. DeG $=$ DeGrey River, Rob $=$ Robe River.

\begin{tabular}{|c|c|c|c|c|c|c|c|c|c|c|c|c|}
\hline Characters & 1 & 2 & 3 & 4 & 5 & 6 & 7 & 8 & 9 & 10 & 11 & 12 \\
\hline \multicolumn{13}{|l|}{ Species } \\
\hline N. douglasi & 1 & 0 & 0 & 0 & 0 & 0 & 0 & 0 & 0 & 0 & 0 & 0 \\
\hline N. straskraba & 1 & 0 & 0 & 0 & 0 & 0 & 0 & 0 & 0 & 0 & 0 & 0 \\
\hline M. pleobranchos & 2 & 1 & 1 & 0 & 1 & 1 & 0 & 1 & 3 & 2 & 1 & 1 \\
\hline P. millsi & 2 & 1 & 1 & 1 & 1 & 1 & 0 & 0 & 0 & 2 & 1 & 1 \\
\hline C. acuminata & 2 & 1 & 1 & 1 & 1 & 1 & 0 & 0 & 1 & 2 & 1 & 1 \\
\hline C. brachybasis & 2 & 1 & 1 & 1 & 1 & 1 & 0 & 0 & 1 & 2 & 2 & 1 \\
\hline C. nudula & 2 & 1 & 1 & 1 & 1 & 1 & 0 & 0 & 1 & 2 & 1 & 1 \\
\hline C. scopula & 2 & 1 & 1 & 1 & 1 & 1 & 0 & 0 & 1 & 2 & 1 & 1 \\
\hline Group H & 2 & 1 & 1 & 1 & 1 & 0 & 1 & 1 & 3 & 2 & 2 & 1 \\
\hline P. fontinalis & 1 & 1 & 1 & 0 & 0 & 1 & 0 & 0 & 2 & 0 & 0 & 0 \\
\hline nr. Wes (DeG) & 1 & 1 & 1 & 1 & 0 & 2 & 0 & 0 & 2 & 1 & 1 & 0 \\
\hline nr. Wes (Rob) & 1 & 1 & 1 & 1 & 0 & 2 & 0 & 0 & 2 & 1 & 1 & 0 \\
\hline
\end{tabular}

\begin{tabular}{lllllllllllllll}
\hline Characters & $\mathbf{1 3}$ & $\mathbf{1 4}$ & $\mathbf{1 5}$ & $\mathbf{1 6}$ & $\mathbf{1 7}$ & $\mathbf{1 8}$ & $\mathbf{1 9}$ & $\mathbf{2 0}$ & $\mathbf{2 1}$ & $\mathbf{2 2}$ & $\mathbf{2 3}$ & $\mathbf{2 4}$ & $\mathbf{2 5}$ & $\mathbf{2 6}$ \\
\hline Species & & & & & & & & & & & & & \\
N. douglasi & 2 & 1 & 1 & 0 & 0 & 0 & 0 & 0 & 1 & 0 & - & 1 & 0 & 0 \\
N. straskraba & 2 & 1 & 1 & 0 & 0 & 0 & 0 & 0 & 1 & 0 & - & 1 & 0 & 0 \\
M. pleobranchos & 2 & 0 & 1 & 1 & 0 & 0 & 0 & 1 & 1 & 1 & 0 & 1 & 1 & 0 \\
P. millsi & 2 & 0 & 1 & 1 & 0 & 0 & 0 & 1 & 1 & 1 & 0 & 1 & 1 & 1 \\
C. acuminata & 2 & 0 & 1 & 1 & 0 & 0 & 0 & 1 & 1 & 1 & 0 & 1 & 1 & 0 \\
C. brachybasis & 2 & 0 & 1 & 1 & 0 & 0 & 0 & 1 & 1 & 1 & 0 & 1 & 0 & 0 \\
C. nudula & 2 & 0 & 1 & 1 & 0 & 0 & 0 & 1 & 1 & 1 & 0 & 1 & 1 & 0 \\
C. scopula & 2 & 0 & 1 & 1 & 0 & 0 & 0 & 1 & 1 & 1 & 0 & 1 & 1 & 0 \\
Group H & 0 & 0 & 1 & 1 & 1 & 0 & 0 & 0 & 0 & 1 & 0 & 0 & 0 & 0 \\
P. fontinalis & 0 & 0 & 0 & 0 & 1 & 0 & 0 & 0 & 0 & 0 & 0 & 1 & 0 & 0 \\
nr. Wes (DeG) & 2 & 0 & 0 & 0 & 1 & 1 & 1 & 0 & 1 & 0 & 1 & 0 & 1 & 1 \\
nr. Wes (Rob) & 2 & 0 & 0 & 0 & 1 & 1 & 1 & 0 & 1 & 0 & 1 & 0 & 1 & 1 \\
\hline
\end{tabular}

articles of the mandibular palp (Table 5). Despite some similarities to Protocrangonyx fontinalis, such as an entire telson and lack of a distal article on the outer ramus of uropod 3 (Figure 5), rugosities on the gnathopods but not on the maxillipedal palps (Figure 6), and short pleopodal rami (Figure 7), the two taxa differ in 14 other characteristics, such as the number of articles in the accessory flagellum of antenna 1, the presence (group $\mathrm{H}$ ) or absence ( $P$. fontinalis) of calceoli on antenna 2 , the relative length of the flagellum to the peduncle of antenna 2, the location of the coxal and sternal gills, the shape of the sternal gills, the shape of the gnathopods and relative size of the carpus, the relative proportion of the articles of the mandibular palp, and setation on pereopods 3 and 4 .

\section{DISCUSSION}

Molecular and morphological data confirmed the distinctiveness of the specimens from group $H$, and verified their status as a new genus and species. Analysis of allozymes from 100 individuals from Spearhole Creek revealed four highly divergent genetic groups, which were characterised by allelic substitutions at a large proportion of loci and high genetic distances. The low sample size of some of these groups, such as F (Chydaekata) and G precludes detailed analysis of genetic diversity within groups, and error associated with small sample sizes and a limited number of loci may bias between-group variation. Nevertheless, these results provide the basis for seeking congruent morphological variation. Hence morphological evidence, which supports the genetic findings, provides a robust framework for identifying unique taxa. Group $F$ was identified as Chydaekata, and group I differed from group $\mathrm{H}$ in a number of characters, including a telson that was nearly fully cleft and that was ornamented with both setae and plumose setae, very small, highly oblique gnathopods, and the outer ramus of uropod 3, which possessed a distal article and had setal tufts along the margin. Only group $G$ has not been confirmed morphologically because only five individuals were present in 

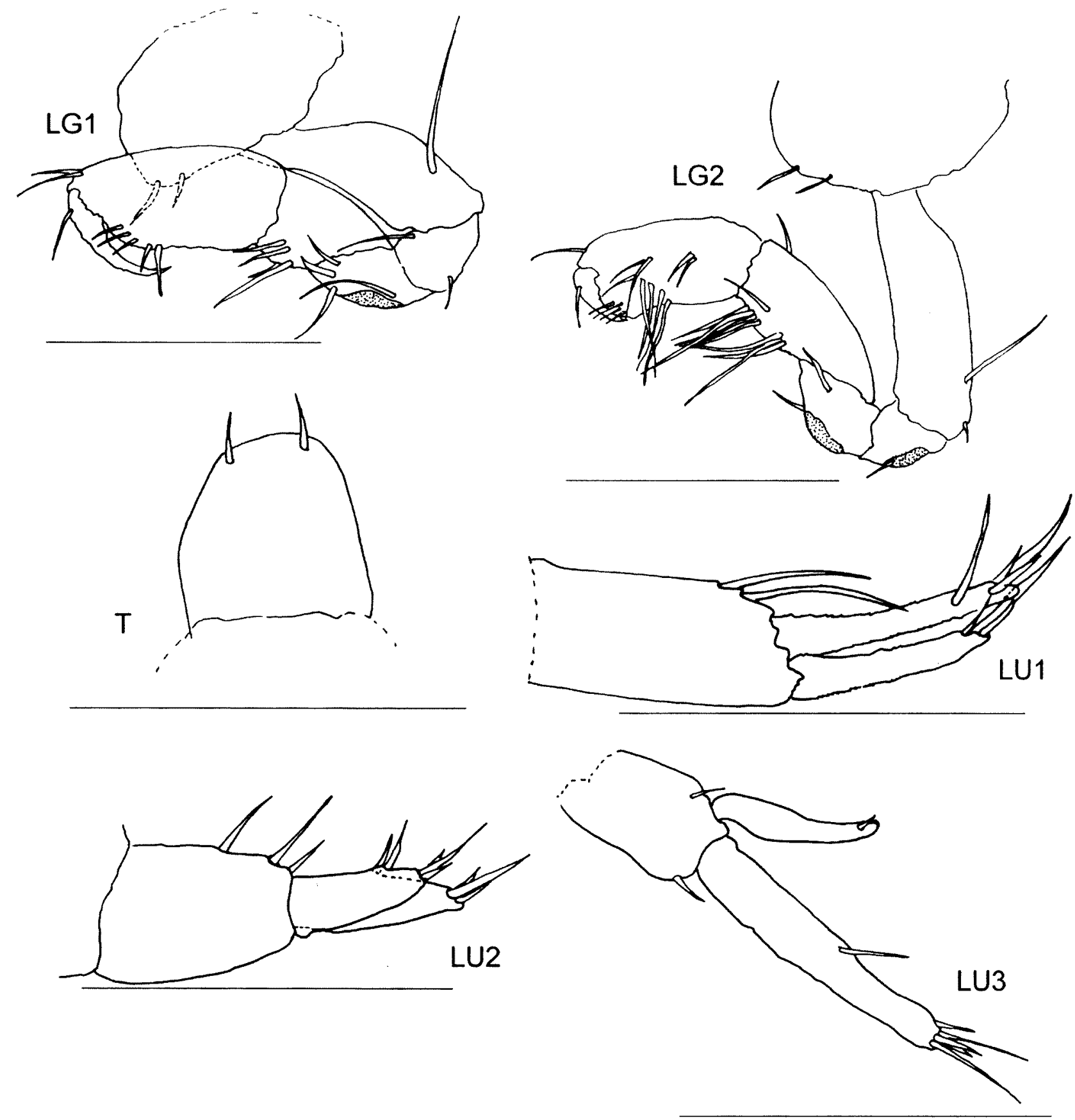

Figure 5 Kraptus linnaci sp. nov, holotype, appendages: gnathopods $(\mathrm{G})$, telson $(\mathrm{T})$, uropods $(\mathrm{U})$ ). $\mathrm{R}=\mathrm{right}, \mathrm{L}=$ left. Scale lines $=200 \mu \mathrm{m}$.

our collections and they were consumed during electrophoresis. On a broader geographical scale, we have analysed genetic diversity in amphipods from 35 bores at eight sites in the Pilbara (Finston and Johnson 2004; Finston et al. 2004), and identified only a single specimen showing genetic affinities to the group $H$ specimens. This specimen, from Seven Mile Creek, differed from group $\mathrm{H}$ by a genetic distance of 0.78 , and in a high proportion of diagnostic loci $(0.56)$. Yet this species is perhaps the closest relative to group $\mathrm{H}$, and may represent a congener. The specimen was consumed for allozyme electrophoresis, so future collections should focus on finding more representatives of this species, in order to determine its morphological relationship to group $\mathrm{H}$.

The distribution of species at Spearhole Creek sheds some light on dispersal capabilities of the genetic groups and on hydrological connections between geological formations at small and large scales. While discrete aquifers were predicted to be contained within the shale formations, the presence of group $\mathrm{H}$ in multiple shale formations 
indicates that movement is possible over these short distances, perhaps through cracks and fissures. The presence of Chydaekata, a widespread genus comprising multiple distinct lineages that occupy separate creek catchments over hundreds of kilometres in the upper Fortescue River basin (Finston et al. 2007), is unlikely to be due to recent migratory events. Such widespread distributions are hypothesised to occur as a result of extended periods of drying, during which time invasions of the groundwater by surface ancestors were followed by isolation and genetic divergence (Bradbury and Williams 1997b; Humphreys 1999, 2001; Finston et al. 2007). The restriction of Chydackata to the calcrete aquifer at Spearhole Creek and its exclusion from the shale deposits may reflect its need for larger void spaces. We conclude that habitat type and connections in groundwater flow are important factors in determining the local movement and distribution of species, while hydrological events and historical processes play a role in shaping broader distributions.

Morphological analysis upheld the distinctiveness of the specimens from group $H$. The specimens do not fit the descriptions of any species, and differ in a number of diagnostic characters at a level greater than that between the other genera in this study. Hence both molecular and morphological evidence support the description of a new genus and species from group $\mathrm{H}$ from Spearhole Creek. While the majority of the evidence suggests the species belongs in the family Paramelitidae, the species from group $\mathrm{H}$ also possesses some characters diagnostic of the neoniphargids, and characters that should exclude it from the paramelitids. Similarly, Protocrangonyx possesses characters of both families, however the weight of evidence places group $\mathrm{H}$ in the paramelitids, whilst the taxonomic position of Protocrangonyx could not be resolved. The characters considered to define these families have changed since their inception in 1977 (Bousfield 1977), with the addition of newly examined material and critical evaluation of the range of acceptable character states (Williams and Barnard 1988, Bradbury and Williams 1997a, Bradbury and Williams 1999). Currently, only two characters appear to separate the families: 1) the presence of rugosities on the gnathopods and palp of maxillipeds in the neoniphargids, and the absence of these structures in the paramelitids; and 2) the presence of sternal gills on segment 7 in the paramelitids, whilst they terminate at segment 6 in the neoniphargids (Bradbury and Williams 1999). Many other characters have overlapping distributions between the two families. For example, the inner lobes of the lower lip are described as being absent in the paramelitids and "poorly to moderately developed" in the neoniphargids (Bousfied 1977), but are absent or indistinct in several neoniphargid genera, such as Neoniphargus Stebbing 1899, Wesniphargus Williams and Barnard 1988, Yulia Williams and Barnard 1988 and Tasniphargus Williams and Barnard 1988 (Williams and Barnard 1988). Similarly, the sternal gills may be absent or simple in the paramelitids, but range from simple to dendritic in the neoniphargids (Bousfield 1977). An important feature of the neoniphargid body plan is the lengthening of the coxae, especially coxae 1-4 (Bousfield 1977), but the coxae are described as "moderately elongate" in such paramelitid genera as Austrogammarus Barnard and Karaman 1983, Antipodeus Williams and Barnard 1988 and Hurleya Straškraba 1966 (Williams and Barnard 1988). Williams and Barnard (1988), while amending the diagnostic characters of the Paramelitidae and Neoniphargidae, highlighted the need for a formal re-diagnosis of these families. The inability to resolve the placement of Protocrangonyx, coupled with the discovery of group $\mathrm{H}$, a new genus and species possessing characters from both families, confirms the need for such a revision, in which rugosities on the gnathopods, which may be present or absent, should be considered a diagnostic character of the paramelitids.

\section{Family Paramelitidae Bousfield 1977}

Kruptus gen. nov.

\section{Type species}

Kruptus linnaei sp. nov.

\section{Diagnosis}

Body subvermiform; pereonites and urosomites lacking dorsal setation; coxae short, coxa 4 not excavate, coxal gill lacking on coxa 7; epimera with few dorsal setae. Sternal gills small, simple, budshaped. Accessory flagellum of antenna 1 of three articles, the first and third being markedly short, and the second being markedly long, about 3 to $4 \times$ as great as the third article. Antenna 2 with type 9 (crangonyctoid) calceoli. Article 1 of mandibular palp markedly longer than wide; article 2 with few setae; article 3 with DE setae; inner lobes of lower lip asymmetrical, poorly developed. Palms of gnathopods weakly oblique to transverse. Row of long setae on medial surface of prodopus of gnathopod 2; rugosities on merus of gnathopod 2; carpi of gnathopod 2 long. Posterior setae on article 2 of pereopods 3 and 4 short. Inner ramus of uropod 3 relatively long, about $1 / 2$ the length of outer ramus; outer ramus lacking the distal article; urosomes of uropods 1 and 2 short, approximately equal in length to peduncles. Telson entire. 

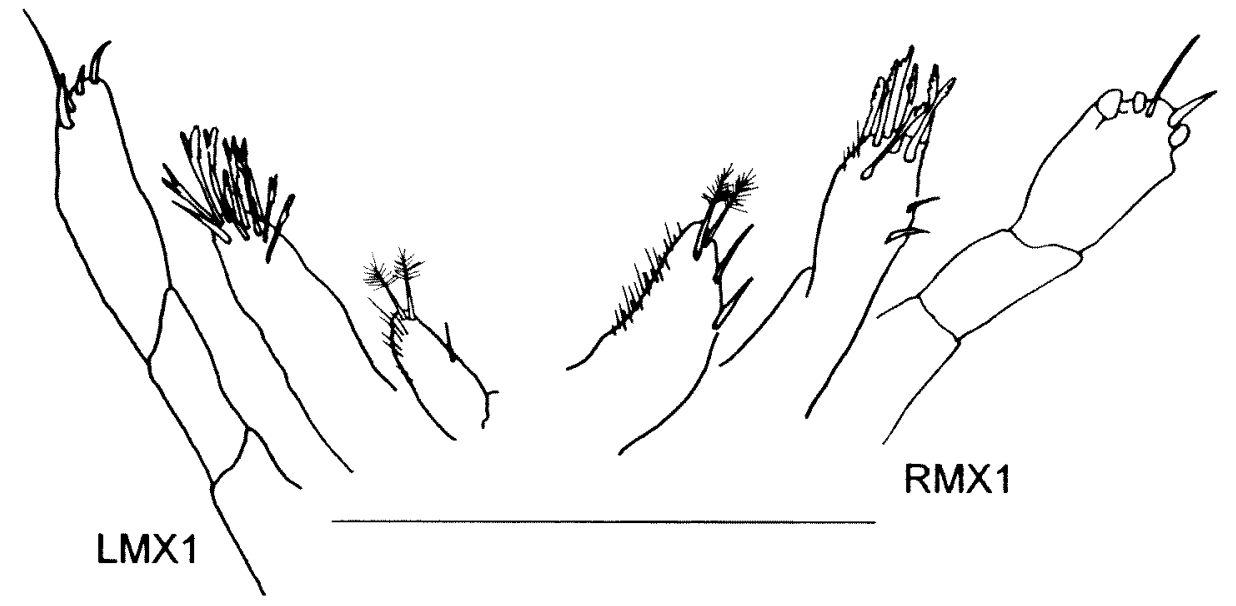

$\mathrm{RMX1}$

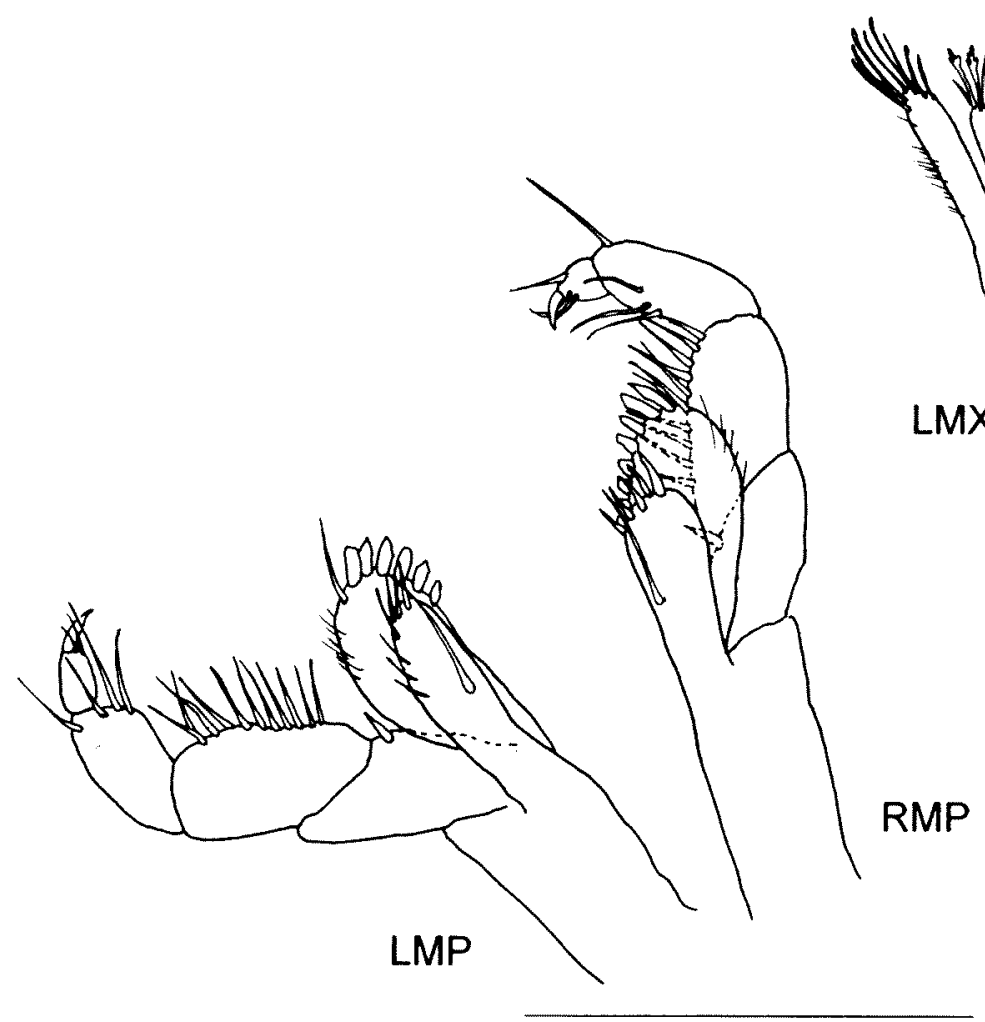

Figure 6 Kruptus limnati sp. nov., holotype, mouthparts: maxilla (MX), maxillipeds (MP). $R=$ right, $L=$ left. Scale lines $=$ $200 \mu \mathrm{m}$.

\section{Distribution}

Kruptus linnaci is known only from Spearhole Creek in the upper Fortescue River drainage basin, Pilbara, Western Australia

\section{Relationships}

Kruptus resembles Pilbarus, Chydackata, and Molina in having weakly oblique or transverse gnathopods. In addition, as in Chydackata, asthetascs are present on antenna 1 and calceoli are present on antenna 2 in the male. Kruptus can be distinguished from these genera by its telson, which is entire, while in the former genera the telson is deeply cleft, ranging from 70 to $90 \%$. Kruptus shares several characteristics with Molina, such as having a complete set of sternal gills (27), but it can be distinguished from Molina by the presence of calceoli on the second antenna in the male, which are absent in Molina, the number of articles in the accessory flagellum, which is three in Kruptus, but six in Molina, and the shape of the sternal gills in Kruptus, which are small buds, while they are sausage-shaped in Molina. Kruptus also shares some traits with Protocrangonyx, such as the lack of the distal article on the outer ramus of uropod 3 , and an entire telson, but can 
be distinguished from that genus by its smaller gnathopods, coxal gill 7 , which is present in Kruptus but absent in Protocrangonyx, the number of articles in the accessory flagellum of antenna 1, which is two in Protocrangony $x$ and three in Kruptus, the lack of calceoli on antenna 2 in Protocrangonyx, the proportion of article 1 of the mandibular palp, which is approximately as long as wide in Protocrangonyx but markedly longer than wide in Kruptus, the proportion of the carpus of gnathopod 2, which is short in Protocrangonyx, but long in Kruptus, and the type of posterior setae on pereopods 3 and 4, which are long in Protocrangonyx and short in Kruptus. Kruptus also shares some characteristics with neonipargids such as Wesniphargus, namely possessing rugosities on the gnathopods, but also in having three articles in the accessory flagellum of antenna 1, possessing calceoli on antenna 2 in the male, having short pleopodal rami with few articles, and possessing short posterior setae on article 2 of pereopods 3 and 4. It also shares traits with Giniphargus in having small, nearly transverse gnathopods, and the carpus of gnathopod 2 elongate and lacking in lobes, however, Kruptus can be distinguished from Wesniphargus by the accessory flagellum of antenna 1, which has three articles, the relatively longer flagellum of antenna 2 , the lack of a coxal gill on pereopod 7 , the small and nearly transverse shape of the gnathopods and relatively long carpus of gnathopod 2, the lack of a cleft in the telson, the small bud-shaped sternal gills, and the long first article of the mandibular palp, and from Giniphargus by its less vermiform body, and lack of the second article on the outer ramus of uropod 3 , which is present and markedly long in Giniphargus.

\section{Etymology}

The genus name comes from the Greek word for 'hidden' (kruptos), to highlight its subterranean distribution and to indicate the presence of cryptic characters belonging to other groups of amphipods. The species name is in recognition of the $300^{\text {th }}$ anniversary of the birth of Carl Linnaeus.

\section{Kruptus linnaei sp. nov.}

Figures $4-7$

\section{Material examined}

\section{Holotype}

Australia: Western Australia: ठ (2.4 mm), Pilbara region, Spearhole Creek, bore GM069, 2316 $57^{\prime \prime} \mathrm{S}$, $119^{\circ} 11^{\prime} 20^{\prime \prime} \mathrm{E}$, October 2001, T. Finston, G. Humphreys, M.S. Johnson (WAM C40037, 2 slides).
Allotype

Australia: Western Australia: $q(2.0 \mathrm{~mm})$, Pilbara region, Spearhole Creek, bore GM019, $23^{\circ} 16^{\prime} 55^{\prime \prime} S$, $119^{\circ} 11^{\prime} 20^{\prime \prime} \mathrm{E}$, October 2001, T. Finston, G. Humphreys, M.S. Johnson (WAM C40034, 2 slides).

\section{Paratypes}

Australia: Western Australia: 3 specimens, Pilbara region, Spearhole Creek, bore GM019, $23^{\circ} 16^{\prime} 55^{\prime \prime S}, 119^{\circ} 11^{\prime} 37^{\prime \prime}$ (WAM C40034); 2 specimens, Spearhole Creek, bore GM039, 2316 $57^{\prime \prime}$, $119^{\circ} 11^{\prime} 48^{\prime \prime}$ E (WAM C40035); 1 specimen, Spearhole

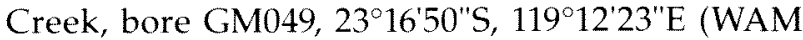
C40036); 7 specimens, Spearhole Creek, bore GM069, 2316 $57^{\prime \prime S}$, 119 11'20"E (WAM C40037); 2 specimens, Spearhole Creek, bore GM118, $23^{\circ} 16^{\prime} 53^{\prime \prime} \mathrm{S}, 119^{\circ} 12^{\prime} 6^{\prime \prime} \mathrm{E}$ (WAM C40038, WAM C40039).

\section{Description}

\section{Male (WAM C40037)}

Head: sinus shallow; antenna 1 having 11 articles on left and 12 on right, peduncle longest article, asthetascs present on articles 3-11. Accessory flagellum short, of three articles, extending to middle of article 2 of the flagellum. Articles 1 and 3 of the accessory flagellum are markedly short, article 2 being markedly long, about $4 \times$ greater than article 3 . Antenna 2 of six articles on left and five articles on right, possessing long, feather-shaped calceoli on articles 1-4, plus one calceolus on the peduncle. Right mandible: palp with three articles, article 2 longest. Article 1 nude; article 2 with small protuberance or notch on ventral surface, followed by two setae; article 3 with four setae on ventral margin, and two setae apically. One seta originates on dorsal surface, nearly apically. Incisor with five teeth; lacinia a flat, lightly serrated plate with a small thumb-like projection and an underlying flat plate with a serrated edge. Molar raised, with a flat grinding surface and one long seta, setal row of very short setae. Two serrated setae arise from base of lacinia. Left mandible: missing. Right maxilla 1: Palp with two articles; article 2 with one apical robust seta plus three very short, blunt projections and one long seta. Inner plate with ten bifid robust setae, some serrate. Outer plate short, conical, about $1 / 2$ the length of the inner plate, and with two plumose setae and fine short setae on outer margin. Left maxilla 1: Palp with two articles; article 2 with three apical robust setae and one long seta. Inner plate with ten bifid robust setae, some serrate. Outer plate short, about $1 / 2$ length of inner plate, conical, and with two apical plumose setae. Right maxilla 2: Inner and outer plates 


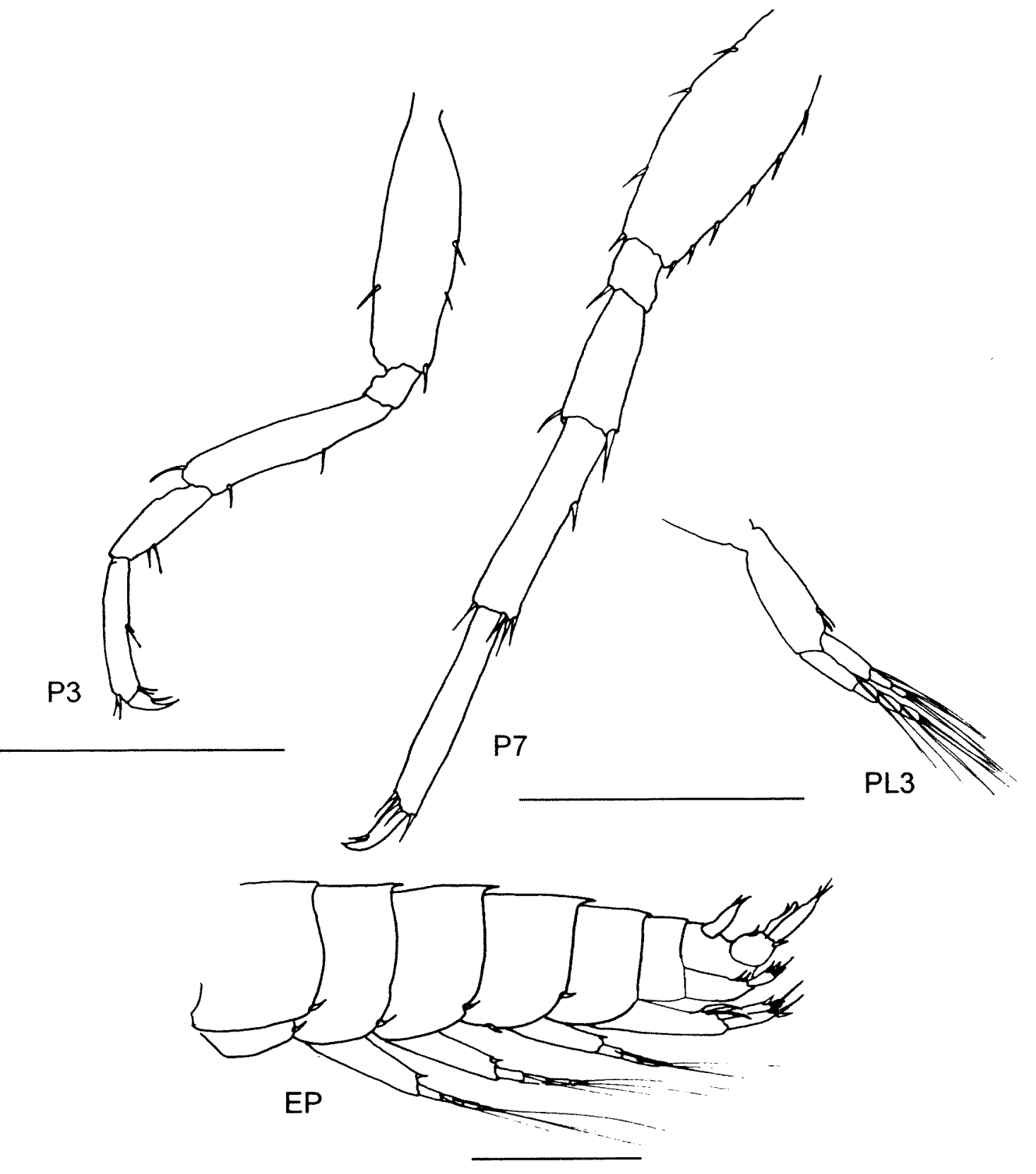

Figure 7 Kruptus limnaei sp. nov, holotype, appendages: pereopod 3 (P3), pereopod 7 (P7), pleopod 3 (PL3) and enlargement of epimera $(E P)$. Scale lines $=200 \mu \mathrm{m}$.

both long, thin, sausage-like. Outer plate with eight long setae, outer margin with few, fine short setae. Inner plate with seven apical setae, inner margin with many fine setae along full length, surface also sparsely covered with fine setae. Left maxilla 2: Inner and outer plates both long, very thin, sausage-like. Inner plate approximately $5 / 6$ the length of outer plate. Outer plate with fine setae on outer margin and nine apical setae, some curved at tip. Inner plate with two plumose apical setae; inner margin with many fine setae. Right maxilliped: palp of four articles. Article 1 with a single seta on inner surface near the base of article 2 . Article 2 with ten setae on inner margin.
Article 3 with three setae on inner margin, near base of dactyl; dactyl with one short seta on inner margin, near base of claw. Outer plate with long, fine setae on outer margin and eight apical broad, flat, setae and one apical seta. Inner plate with six robust setae at apex plus one sub-marginal seta that originates at the approximate midpoint. Left maxilliped: palp with four articles. Article 1 with single seta, sub-apical, at inner corner near base of article 2 ; article 2 with 11 setae in a row on inner margin; article 3 with a single apical seta on outer corner and three on inner margin at base of article 4. Outer plate bulbous, with seven fine setae on outer margin and one apical seta; inner margin 
with six broad, curved robust setae. Inner plate with four apical setae, three fine, sub-marginal setae on outer margin and inner margin with three setae. Upper lip: relatively symmetrical, with two patches of dense short setae at apex corners. Lower lip: outer lobes with short setae at apices; inner lobes weakly developed, asymmetrical, nearly absent on right side and covered with short setae. Body: subvermiform in shape; coxae 2-4 displaced from their corresponding pereonites; coxa 4 not excavate. Cuticle relatively smooth with little setation. Coxal gills present on coxae 3-7; sternal gills present on pereonites $2-7$, increasing in size posteriorly. Gnathopod 1: prodopus nearly mittenform, palm slightly oblique, convex, and with four sub-marginal setae in a row at base of palm, ending in one robust seta. Carpus short, about $1 / 2$ length of prodopus, and with four submarginal setae. Merus with one marginal seta and small rugose patch on ventral surface. Ischium with short seta near base. Basis with one seta near base. Coxa extended anteriorly with two setae on anterior margin. Gnathopod 2: prodopus mittenform, slightly smaller than gnathopod 1, palm nearly transverse, with four setae at corner. Base of dactyl with one seta; prodopus with one long seta on dorsal margin, near base of dactyl, and three setal rows on surface of prodopus, two on medial surface, each with two setae and one near ventral margin, composed of five setae. Carpus extended, approximately equal in length to prodopus and bearing two setal rows, the anterior with four and the posterior with three setae. Merus with one seta and small rugose patch on ventral surface, and one seta on medial surface. Ischium with one seta and small rugose patch on ventral surface. Basis with one seta near apical corner and one long seta on posterior margin. Coxa expanded anteriorly, and with two anterior setae. Pereopods 3-4: with sparse, short setation (one to two setae per article) on posterior margin, merus of each slightly lobate anteriorally, dactyls with single short seta. Pereopods 5-7: with three to four robust setae at base of each article, dactyls with single seta; pereopod 7 longest. Pleopods 1-3: peduncle with one retinacula and one accessory retinacula, rami with three to four articles. Uropod 1: Peduncle with two long setae on dorsal margin near apex; rami relatively short; inner ramus equal in length to peduncle and outer ramus approximately $0.9 \times$ the length of the peduncle, both rami terminating in two short and one long setae. Inner ramus also with one long sub-apical seta. Uropod 2: peduncle with three short robust setae, one sub-marginal about halfway along outer margin, and two subapically, one on inner margin near base of inner ramus and one medially. Inner and outer rami clearly shorter than peduncle, both terminating in three apical and one sub-apical seta. Inner ramus $0.85 \times$ the length of the peduncle, outer ramus approximately $0.65 \times$ the length of the peduncle. Uropod 3: outer ramus $2.0 \times$ the length of peduncle, peduncle bearing one robust seta at outer distal corner. Outer ramus with one robust seta on outer margin, and one long seta on inner margin, and terminating in two apical robust setae and one short and two long apical setae; distal article of uropod 3 absent. Inner ramus leaf-shaped, $1.15 \times$ the length of peduncle, tip is recurved, with one tiny seta at sub-apex. Telson: entire, with one apical seta at each corner.

\section{Female (WAM C40034)}

Similar to male except in the following characteristics:

Head: antenna 1 having ten articles on both left and right, with asthetascs on articles 5-9. Antenna 2 having five articles on both left and right and bearing no calceoli. Right mandible; article 2 long, rectangular, lacking notch on ventral surface; margin straight with one long seta; article 3 with three setae near margin on inner and outer surfaces, and one long seta and two short setae apically. Left mandible: palp with three articles; article 2 longest. Article 1 with one marginal seta, medially, and one short seta sub-apically, near base of article 2 . Article 2 with two setae on the dorsal surface and with two setal rows on inner margin, the distal row containing four setae and the proximal row containing three setae. Article 3 with two rows of two setae on the dorsal surface and with a setal row on inner margin containing three setae, and three apical and three sub-apical setae. Incisor with five teeth; lacinia a flat plate with five teeth. Molar raised with a flat grinding surface and one short seta, and a setal row of very short setae. Three serrate setae arise from base of lacinia, plus one plumose seta. Right maxilla 1: Article 2 of palp with five apical robust setae, article 1 nude. Left maxilla 1: Article 2 with four apical setae of similar length, and one sub-apical, sub-marginal seta. Right maxilliped: peduncle with long seta instead of a robust seta. Left maxilliped: peduncle with long seta instead of a robust seta. Gnathopod 1: prodopus with three sub-marginal setae in row near base of palm, merus with three marginal setae. Gnathopod 2: distinctly smaller than gnathopod 1; prodopus lacking dorsal setae on margin, ischium lacking rugose patch. Uropod 1: lacking two long setae on peduncle; instead with three short setae on each side dorsally, plus one very large, robust seta sub-apically near base of outer ramus. Uropod 2: peduncle with a single robust seta sub-apically near base of inner ramus. Uropod 3: peduncle nude, outer ramus with two setae on inner margin 
and terminating in three robust setae and one long seta.

\section{Character variation}

The number of articles in the flagella of antennae 1 and 2 varies from $10-11$ and 5-6, respectively among individuals, and sometimes between left and right of the same individual. The prodopus and carpus of the gnathopods are slightly lobate post-ventrally in some individuals, and the degree of lobateness of the merus of pereopods 3 and 4 differs among individuals. The angle of the palm of gnathopod 1 varies among individuals from slightly oblique to moderately oblique. Setation differs on the peduncle and rami of the uropods and on the articles of gnathopods 1 and 2, as well as on the mouthparts. Most differences occur as changes in the number of setae, however, changes in the structure of the setae sometimes occur, particularly on the peduncle of uropod 1 and the maxillipeds.

\section{ACKNOWLEDGEMENTS}

This project was funded by BHP-Billiton Pty. Ltd, Pilbara Iron Pty. Ltd., and ARC Linkage grant LP0349199. Samples were collected with the assistance of Biota Environmental Sciences. Many thanks to Susan Johnson for the illustrations, Garth Humphreys for overall coordination of the sampling, and Jason Pepper and Sally Madden for information about the geological structure of Spearhole Creek. Thanks to Adrian Pinder of the Department of the Environment and Conservation for providing samples of neoniphargids. Two anonymous reviewers gave helpful comments on an earlier draft of the manuscript.

\section{REFERENCES}

Barnard, J.L. and Karaman, G.S. (1983) Australia as a major evolutionary centre for Amphipoda (Crustacea). Memoirs of the Australian Musem 18: 45-61.

Barnard, J.L. and Williams, W.D. (1995). The taxonomy of the Amphipods (Crustacea) from Australian fresh waters: part 2. Recorts of the Australim Musem 47 : 161-201.

Bousfield, E.L. (1973). Shallow-inater Gammaridean Amphipoda of New England. Comell University Press: Ithaca, New York.

Bousfield, E.L. (1977). A new look at the systematics of gammaroidean Amphipoda of the world. Crustacena, Supplement 4: 282-316

Bradburv, 1.H. (2000). Western Australian stygobiont amphipods (Crustacea: Paramelitidae) from the Mit Newman and Millstream regions. Recerds of the Westem Australian Museam, Supplement 60: 1-102.

Bradbury, J.H. and Williams, W.D. (1996). Freshwater amphipods from Barrow Island, Western Australia. Records of the Australian Musem 48: 33-.-74.
Bradbury, J.H. and Williams, W.D. (1997a). The amphipod (Crustacea) stygofauna of Australia: Description of new taxa (Melitidae, Neoniphargidae, Paramelitidae), and a synopsis of known species. Records of the Australian Museum 49: 249-341.

Bradbury, J.H. and Williams, W.D. (1997b). Amphipod (Crustacea) diversity in underground waters in Australia: An Aladdin's Cave. Momoirs of the Musemm of Victoria $56: 513-519$

Bradbury, J.H. and Williams, W.D. (1999). Key to and checklist of the inland aquatic amphipods of Australia. Technical Reports of the Australian Museam 14: 1-21.

Eberhard, S.M., Halse, S.A. and Humphreys, W.F. (2005a). Stygofauna in the Pilbara region, north-west Western Australia: A review. Joumal of the Royal Sociely of Western Australia 88: 167-176

Eberhard, S.M., Halse, S.A., Scanlon, M.D., Cocking, J.S. and Barron, H.J. (2005b). Assessment and conservation of aquatic life in the subsurface of the Pilbara region, Western Australia. Procedings of the World Subterranean Biodiversity Symposium, University Chunde Bernard of Lyon 1, Villewrbanne, France: 61-68.

Finston, T.L. and Johnson, M.S. (2004). Geographic patterns of genetic diversity in subterranean amphipods of the Pilbara, Western Australia. Marint and Freshenter Research 55: 619-628.

Finston, T.L., Bradbury, J.H., Johnson, M.S. and Knott, B. (2004). When morphology and molecular markers conflict: A case history of subterranean amphipods from the Pilbara, Western Australia. Animal Biodicersity and Conservation 27: 83-94.

Finston, T.L., Johnson, M.S., Humphreys, W.F., Eberhard, S. and Halse, S.A. (2007). Cryptic speciation in two widespread subterranean amphipod genera reflects historical drainage patterns in an ancient landscape. Molecular Ecology 16: 355-365.

Harmsworth, R.A., Kneeshaw, M., Morris, R.C., Robinson, C.J., and Shrivastava, P.K. (1990). BIF-derived iron ores of the Hamersley Province. In: F.E. Hughes (ed.) Geology of the Mineral Deposits of Australia and Papua New Guinea: pp. 617-642. The Australasian Institute of Mining and Metallurgy: Melbourne.

Humphreys, W.F. (1999). Relict stygofaunas living in sea salt, karst and calcrete habitats in arid northwestern Australia contain many ancient lineages. III. W. Ponder and D. Lunney (eds.) The Other 99\%. The Conseriation ant Biodicersity of Incertebrates: $\mathrm{pp}$. 219-227. Transactions of the Royal Society of New South Wales: Mosman

Humphreys, WF. (2001). Groundwater calcrete aquifers in the Australian arid zone, the context to an unfolding plethora of stygal biodiversity. Reconts of the Western Anstralian Muse'um, Supploment 64: 63-83.

Lefebure, T., Douady, C..., Gouy, M., Trontelj, P., Briolay, I. and Gibert, I. (2006). Pylogeography of a subterranean amphipod reveals cryptic diversity and dynamic evolution in extreme environments. Molecular Ecology 15: $1797-1806$.

Lowry, I.K. and Springthorpe, R.T. (2001). Amphipoda: Families. Version 1: 2 September 2001. http:lowate. crustaciane't 
Nei, M. (1972). Genetic distance between populations. American Naturalist 106: 283-292.

Nicholls, G.E. (1926). Protocrangonyx fontinalis, a new blind freshwater amphipod from Western Australia. Journal of the Royal Society of Western Australia 12: $71-78$.

Page, R.D.M. (2001). Nexus Data Editor for Windows. http//:taxonomy/zoology/gla.ac.uk/rod/rod.html

Stebbing, T.R.R. (1899). Amphipoda from the Copenhagen Museum and other sources. Transactions of the Linnean Society of London, (2, Zoology) 8: 395-432.
Straškraba, M. (1966). Hurleya kalamundae n.g.n.sp. (Amphipoda, Gammaridae) from subterranean waters of Western Australia. International Journal of Speleology 2: 291-295.

Swofford, D.L. (2001). PAUP*, Phylogenetic Analysis Using Parsimony ( ${ }^{*}$ and Other Methods). Version 4.0b10. Sinauer Associates: Sunderland, Massachusetts.

Williams, W.D. and Barnard, J.L. (1988). The taxonomy of crangonyctoid Amphipoda (Crustacea) from Australian fresh waters: foundation studies. Records of the Australian Museum, Supplement 10: 1-180.

Manuscript received 31 March 2008, accepted 11 July 2008. 